\title{
BMJ Open Self-reported hypoglycaemia in patients with type 2 diabetes treated with insulin in the Hoorn Diabetes Care System Cohort, the Netherlands: a prospective cohort study
}

Simone P Rauh, ${ }^{1,2}$ Femke Rutters, ${ }^{1,2}$ Brian L Thorsted, ${ }^{3}$ Michael L Wolden, ${ }^{3}$ Giel Nijpels, ${ }^{2,4}$ Amber A W A van der Heijden, ${ }^{2,4}$ Iris Walraven, ${ }^{1,2}$ Petra J Elders, ${ }^{2,4}$ Martijn W Heymans, ${ }^{1,2}$ Jacqueline M Dekker ${ }^{1,2}$

To cite: Rauh SP, Rutters F, Thorsted BL, et al. Selfreported hypoglycaemia in patients with type 2 diabetes treated with insulin in the Hoorn Diabetes Care System Cohort, the Netherlands: a prospective cohort study. BMJ Open 2016;6:e012793. doi:10.1136/bmjopen-2016012793

- Prepublication history and additional material is available. To view please visit the journal (http://dx.doi.org/ 10.1136/bmjopen-2016012793).

Received 24 May 2016 Revised 4 August 2016 Accepted 24 August 2016

CrossMark

For numbered affiliations see end of article.

Correspondence to

Simone P Rauh;

s.rauh@vumc.nl

\section{ABSTRACT}

Background: Our aim was to study the prevalence of self-reported hypoglycaemic sensations and its association with mortality in patients with type 2 diabetes (T2D) treated with insulin in usual care.

Methods: Demographics, clinical characteristics and mortality data were obtained from 1667 patients with T2D treated with insulin in the Hoorn Diabetes Care System Cohort (DCS), a prospective cohort study using clinical care data. Self-reported hypoglycaemic sensations were defined as either mild: events not requiring help; or severe: events requiring help from others (either medical assistance or assistance of others). The association between hypoglycaemic sensations and mortality was analysed using logistic regression analysis.

Results: At baseline, 981 patients (59\%) reported no hypoglycaemic sensations in the past year, $612(37 \%)$ reported only mild sensations and $74(4 \%)$ reported severe hypoglycaemic sensations. During a median follow-up of 1.9 years, 98 patients (5.9\%) died. Reporting only mild hypoglycaemic sensations was associated with a lower mortality risk (OR 0.48 , $95 \% \mathrm{Cl} 0.28$ to 0.80 ), while reporting severe sensations was not significantly associated with mortality (OR $0.76,95 \% \mathrm{Cl} 0.33$ to 1.80 ), compared with reporting no hypoglycaemic sensations, and adjusting for demographic and clinical characteristics. Sensitivity analyses showed an OR of 1.38 (95\% $\mathrm{Cl} 0.31$ to 6.11 ) for patients reporting severe hypoglycaemic sensations requiring medical assistance.

Conclusions: Self-reported hypoglycaemic sensations are highly prevalent in our insulin-treated T2D population. Patients reporting hypoglycaemic sensations not requiring medical assistance did not have an increased risk of mortality, suggesting that these sensations are not an indicator of increased short-term mortality risk in patients with T2D.

\section{Strengths and limitations of this study}

Little is known about the prevalence of selfreported hypoglycaemic sensations in patients with type 2 diabetes treated with insulin in usual care. We found that $41 \%$ of our patients reported hypoglycaemic sensations in the past year.

- Objectively measured hypoglycaemia has been associated with mortality in patients with type 2 diabetes. However, not all patients might regularly perform self-tests, so self-reported hypoglycaemic sensations might better reflect hypoglycaemia as experienced in everyday life. We found that insulin-treated patients with type 2 diabetes treated in usual care who reported hypoglycaemic sensations not requiring medical assistance did not have an increased risk of mortality.

- Hypoglycaemic sensations that required medical assistance were non-significantly associated with higher mortality risk.

\section{INTRODUCTION}

Hypoglycaemic events and hypoglycaemic sensations are major side effects of glucoselowering therapy in patients with type 2 diabetes (T2D). Hypoglycaemia is associated with a lower quality of life ${ }^{12}$ and has been suggested to be associated with an increased risk of cardiovascular events, cardiovascular mortality and all-cause mortality. ${ }^{3-12}$

Up until now, the reported prevalence of hypoglycaemia in trials and observational research was mostly based on glucose measurements $^{3-5}$ 7-10 and/or based on events registered in medical records: ${ }^{7-10}$ hypoglycaemic events. This type of data source might lead to an underestimation of mild hypoglycaemic events-events that can be resolved by 
the patient without help from others. Moreover, in clinical practice, not all patients with T2D might regularly perform self-testing of their glucose levels and patients consult their general practitioner about experiencing hypoglycaemic sensations without confirmation by glucose measurement. Therefore, self-reported hypoglycaemic sensations might better reflect hypoglycaemia as experienced in everyday life by patients with T2D. However, in the literature, data are lacking on the prevalence of self-reported hypoglycaemic sensations in patients with T2D treated in usual care.

Recently, a prospective study showed that self-reported severe hypoglycaemic sensations were associated with a 3.4-fold increased mortality risk during a 5-year follow-up in $\sim 1000$ patients with type 1 and T2D. ${ }^{13}$ With regard to self-reported mild hypoglycaemia, conflicting results have been found in different populations: selfreported mild hypoglycaemic sensations were associated with a non-significantly increased mortality risk in the previously mentioned study. ${ }^{13}$ In contrast, self-reported mild hypoglycaemia was associated with a significantly lower mortality risk in another study in patients with T2D and high cardiovascular risk. ${ }^{4}$ These studies used mixed diabetes cohorts with no information available on type of diabetes medication or high-risk groups. Therefore, evidence is needed about the frequency of self-reported mild and severe hypoglycaemic sensations in the general T2D population and the associated mortality risk.

Hypoglycaemic events and sensations are more prevalent in patients with diabetes treated with insulin compared with oral glucose-lowering medication, ${ }^{14-16}$ and different mechanisms might play a role in hypoglycaemia in patients treated with different medication types. ${ }^{17}$ No previous observational studies have focused on the prevalence of self-reported hypoglycaemic sensations in insulin-treated patients with T2D and its association with mortality. Therefore, the objective of our study was to evaluate the prevalence of self-reported mild and severe hypoglycaemic sensations in insulintreated patients with T2D treated in usual care, and to investigate the association between self-reported mild and severe hypoglycaemic sensations and mortality.

\section{METHODS}

\section{Study population}

Data were obtained from the Hoorn Diabetes Care System Cohort, the Netherlands (DCS), a prospective population-based cohort study using clinical care data. Since 1998, patients with T2D living in the region of West-Friesland visit the DCS annually to receive diabetes education-including information on how to recognise hyperglycaemia and hypoglycaemia-and to undergo a physical examination, including the assessment of diabetes-related risk factors and complications. Details on the DCS care system have been described previously. ${ }^{18}$
Since 2010, the annual visit includes questions concerning hypoglycaemic sensations in the past year.

For the current study, patients were included when they visited the DCS in 2010, 2011 or 2012 after being treated with insulin for at least 1 year $(\mathrm{N}=1832)$. When no data on self-reported hypoglycaemic sensations were available, patients were excluded $(\mathrm{N}=165)$. We defined the baseline visit as the first annual visit after the patient had been using insulin for at least 1 year. The baseline visit could therefore contain data from the 2010,2011 or 2012 visit and patients could have one, two or three measurements of self-reported hypoglycaemic sensations during follow-up. When no questions on hypoglycaemic sensations were answered at the first annual visit after the patient had been using insulin for at least 1 year, this visit was not taken into account and the next annual visit was considered the baseline visit.

\section{Measures}

Hypoglycaemic sensations were self-reported in an interview by a medical assistant and were determined using the following questions: did you experience hypoglycaemia in the past year (yes/no)? If yes, what kind of symptoms did you experience: dizziness, dreaming, feeling restless, headache when getting out of bed, hunger, mood swings, palpitations, snoring, sweating during the night, tingling sensations around the mouth, trembling or other? Also, if yes, how many hypoglycaemic events did you experience where help from others was not needed (number per year/per month/per week/per day)? How many hypoglycaemic events did you experience that required help from others (number per year/per month/per week/per day)? If help was required, was medical assistance needed or was assistance of others needed? Measurements of blood glucose levels were not available.

Mild hypoglycaemic sensations were defined as hypoglycaemic events not requiring help from others. Severe hypoglycaemic sensations were defined as events requiring help from others, that is, either medical assistance or assistance of others. ${ }^{18}{ }^{19}$ Patients were divided into three categories: patients who reported no hypoglycaemic sensations, only mild hypoglycaemic sensations or any severe hypoglycaemic sensations during follow-up.

Information on mortality date was derived from the Municipal Personal Records Database up to 1 January 2013. No information on cause of death was available.

Information on current medication use was registered by checking dispensing labels brought by patients. Type of insulin was categorised in two groups based on the Anatomical Therapeutic Chemical Classification System (ATC codes): ${ }^{20}$ (1) only intermediate/long acting (A10AC or A10AE); (2) combination of fast and intermediate/long acting (either A10AD or a combination of fast acting (A10AB) and intermediate/long acting (A10AC or A10AE)).

Weight, height, systolic blood pressure (SBP), diastolic blood pressure (DBP), retinopathy, glycated haemoglobin (HbA1c) 
levels and urinary albumin-creatinine (UAC) ratio were measured in a standardised way as described previously. ${ }^{18}$

Hypertension was defined as an $\mathrm{SBP} \geq 140 \mathrm{~mm} \mathrm{Hg}$, a $\mathrm{DBP} \geq 90 \mathrm{~mm} \mathrm{Hg}$ or use of antihypertensive medication. Retinopathy was divided into three categories: no retinopathy (EURODIAB ${ }^{21}$ grade 0 ), mild retinopathy (grade 1-3) and severe retinopathy (grade 4-5). Estimated glomerular filtration rate (eGFR) was calculated using the Modification of Diet in Renal Disease (MDRD) formula.

Cardiovascular history was self-reported: at the first visit to the DCS, patients were asked if they had ever experienced a cerebral vascular accident (CVA), myocardial infarction (MI) or transient ischaemic attack (TIA). At all annual visits, patients were asked about events in the past year. Cardiovascular history was dichotomised (yes/ no; CVA, MI or TIA before baseline). Smoking was selfreported (no/former/current smoking) and was dichotomised in former+current/no. Diabetes duration was reported by the patient's general practitioner. Socioeconomic status (SES) was self-reported based on highest completed educational level and was categorised into three groups: low (no completed education/ primary education/secondary education-practical training); middle (prevocational secondary education/ vocational training/general secondary education or preuniversity education); and high (professional university education/university).

\section{Statistical analysis}

Baseline prevalence of mild and severe self-reported hypoglycaemic sensations is presented as number and percentage. Baseline characteristics are presented as number and percentage, mean $\pm \mathrm{SD}$ or median (IQR) for skewed distributions. Characteristics are shown for the total population and stratified for type of self-reported hypoglycaemic sensations during follow-up. Differences between groups were tested using independent samples Student's t-tests (continuous variables), Mann-Whitney's $\mathrm{U}$ tests (skewed distributions) and $\chi^{2}$ statistics (dichotomous and categorical variables), including tests for trends for ordinal categorical variables.

Logistic regression analysis was used to analyse the association between hypoglycaemic sensations and mortality. Adjusted models were constructed adjusting for sex and baseline values of age, diabetes duration, SES, body mass index (BMI), HbAlc, smoking, hypertension, use of metformin, use of sulfonylurea (SU), retinopathy, eGFR, UAC ratio and cardiovascular disease (CVD) history. For continuous confounders, linearity was checked and, if necessary, variables were categorised. Since the number of events limited adjusting for all these possible confounders in one model, separate models were constructed correcting for one confounder at a time. Additionally, one model was constructed with a combination of confounders, adjusting for sex, age, diabetes duration $(</ \geq 10$ years $)$, HbAlc level $(</ \geq 7 \%(53 \mathrm{mmol} / \mathrm{mol}))$, hypertension, smoking, use of SU, and microvascular or macrovascular complications (yes/no), defined as either having retinopathy, CVD history, an eGFR value $<60$ or a UAC ratio $\geq 3.5 \mathrm{mg} / \mathrm{mmol}$ for women or $\geq 2.5 \mathrm{mg} / \mathrm{mmol}$ for men.

All statistical analyses were performed using IBM SPSS statistics V.20.

\section{Sensitivity analyses}

The first sensitivity analysis distinguished between severe hypoglycaemic sensations requiring non-medical or medical assistance.

Second, the combination of mild and severe hypoglycaemic sensations was studied by categorising type of self-reported hypoglycaemic sensations in four categories: no hypoglycaemic sensations, only mild, both mild and severe, or only severe hypoglycaemic sensations during follow-up.

Third, it has been suggested that frequent mild hypoglycaemic events might protect against the effects of a severe hypoglycaemic event. ${ }^{3}$ Therefore, we evaluated whether a dose-response association was observed between mortality and the average number of reported mild hypoglycaemic events per year, in quartiles. For this analysis, only patients who did not report severe hypoglycaemic sensations were taken into account. In addition, to rule out a possible survival effect, we evaluated whether a dose-response association was observed when only taking into account the number of reported mild hypoglycaemic events reported at baseline, again in quartiles.

Fourth, we evaluated whether differences in follow-up duration between patients affected the results. Therefore, generalised linear models with a follow-up duration on the natural logarithmic scale as an offset variable were introduced in the models.

Fifth, patients who had missing values on all questions regarding hypoglycaemic sensations at the first annual visit after they had been using insulin for at least 1 year were excluded from the analyses.

Finally, we checked for possible interaction between mild and severe hypoglycaemic sensations, and between hypoglycaemic sensations and cardiovascular history (yes/no), age $(</ \geq 70$ years), sex and use of SU.

\section{RESULTS}

\section{Population characteristics}

The mean age at baseline was 67.2 years (SD 11.7 years), $47 \%(\mathrm{~N}=784)$ were women and the mean duration of diabetes at baseline was 11.5 years (IQR 7.9-15.9 years). The characteristics of the total population and those stratified for type of hypoglycaemic sensations reported during follow-up are summarised in table 1. Compared with the patients who reported no hypoglycaemic sensations during follow-up, patients reporting hypoglycaemic sensations had a significantly longer diabetes duration, longer duration of insulin use, longer follow-up duration, and were more often treated with a combination of both fast-acting and intermediate-acting/long-acting 
Table 1 Patient characteristics according to severity of hypoglycaemia during follow-up

\begin{tabular}{|c|c|c|c|c|}
\hline & $\begin{array}{l}\text { Total group } \\
(\mathrm{N}=1667)\end{array}$ & $\begin{array}{l}\text { No } \\
\text { hypoglycaemia } \\
(\mathrm{N}=804(48 \%))\end{array}$ & $\begin{array}{l}\text { Only mild } \\
\text { hypoglycaemia } \\
(\mathrm{N}=744(45 \%))\end{array}$ & $\begin{array}{l}\text { Severe } \\
\text { hypoglycaemia } \\
(\mathrm{N}=119(7 \%))\end{array}$ \\
\hline \multicolumn{5}{|l|}{ Baseline characteristics } \\
\hline Age, years & $67.2 \pm 11.7$ & $68.7 \pm 12.2$ & $65.6 \pm 11.0^{*}$ & $67.7 \pm 12.3$ \\
\hline Women & $784(47 \%)$ & $364(45 \%)$ & $357(48 \%)$ & $63(53 \%)$ \\
\hline Diabetes duration, years & $11.5(7.9-15.9)$ & $11.2(7.3-14.9)$ & $12.0(8.2-16.5)^{*}$ & $12.1(8.2-18.4)^{*}$ \\
\hline Duration of insulin use, years & $4.6(2.1-7.6)$ & $4.3(1.8-6.5)$ & $4.9(2.7-8.7)^{\star}$ & $5.5(3.8-10.1)^{*}$ \\
\hline \multicolumn{5}{|l|}{ Type of insulin } \\
\hline Only intermediate/long acting & $714(43 \%)$ & 419 (52\%) & $266(36 \%)^{\star}$ & $29(24 \%)^{*}$ \\
\hline Combination of fast and intermediate/long acting & $885(53 \%)$ & $341(42 \%)$ & $459(62 \%)^{*}$ & $85(71 \%)^{*}$ \\
\hline \multicolumn{5}{|l|}{ Use of oral antidiabetic medication (next to insulin) } \\
\hline No oral antidiabetic medication & $416(25 \%)$ & $177(22 \%)$ & $194(26 \%)$ & $45(38 \%)^{*}$ \\
\hline Only metformin & $642(39 \%)$ & $285(35 \%)$ & $305(41 \%)^{*}$ & $52(44 \%)$ \\
\hline Only SU & $95(6 \%)$ & $65(8 \%)$ & $29(4 \%)^{*}$ & $1(1 \%)^{*}$ \\
\hline Metformin and SU & $449(27 \%)$ & $238(30 \%)$ & $190(26 \%)$ & $21(18 \%)^{\star}$ \\
\hline Other† & $65(4 \%)$ & $39(5 \%)$ & $26(3 \%)$ & 0 \\
\hline $\mathrm{HbA} 1 \mathrm{c}, \%(\mathrm{mmol} / \mathrm{mol})$ & $7.6 \pm 1.2(60 \pm 13)$ & $7.6 \pm 1.2(60 \pm 12)$ & $7.5 \pm 1.1(58 \pm 12)$ & $7.8 \pm 1.3(62 \pm 14)$ \\
\hline $\mathrm{BMI}, \mathrm{kg} / \mathrm{m} \ddagger$ & $31.3 \pm 5.9$ & $31.6 \pm 5.8$ & $31.2 \pm 5.9$ & $30.5 \pm 6.2$ \\
\hline Smoking & $342(21 \%)$ & $160(20 \%)$ & $156(21 \%)$ & $26(22 \%)$ \\
\hline UAC ratio, $\mathrm{mg} / \mathrm{mmol}$ & $2.0(0.8-6.4)$ & $2.1(0.9-6.9)$ & $1.9(0.8-5.9)$ & $2.3(0.8-4.8)$ \\
\hline eGFR & $80.3 \pm 24.9$ & $79.6 \pm 25.9$ & $81.2 \pm 23.3$ & $79.3 \pm 27.0$ \\
\hline Hypertension $\ddagger$ & $1411(85 \%)$ & $685(85 \%)$ & $626(84 \%)$ & $100(84 \%)$ \\
\hline $\mathrm{SBP}, \mathrm{mm} \mathrm{Hg}$ & $144.3 \pm 22.1$ & $144.7 \pm 22.6$ & $143.9 \pm 21.6$ & $143.9 \pm 21.7$ \\
\hline $\mathrm{DBP}, \mathrm{mm} \mathrm{Hg}$ & $76.4 \pm 9.3$ & $76.7 \pm 10.0$ & $76.2 \pm 8.5$ & $75.7 \pm 9.1$ \\
\hline Use of antihypertensive medication & $1222(73 \%)$ & $590(73 \%)$ & $548(74 \%)$ & $84(71 \%)$ \\
\hline Cardiovascular history§ & $339(20 \%)$ & $153(19 \%)$ & $156(21 \%)$ & $30(25 \%)$ \\
\hline CVA & $65(4 \%)$ & $34(4 \%)$ & $25(3 \%)$ & $6(5 \%)$ \\
\hline $\mathrm{MI}$ & $218(13 \%)$ & $101(13 \%)$ & $98(13 \%)$ & $19(16 \%)$ \\
\hline TIA & $99(6 \%)$ & $39(5 \%)$ & $51(7 \%)$ & $9(8 \%)$ \\
\hline \multicolumn{5}{|l|}{ Retinopathy } \\
\hline No & $1164(70 \%)$ & $563(70 \%)$ & $524(70 \%)$ & $77(65 \%)^{\star}$ \\
\hline Mild & $78(5 \%)$ & $28(4 \%)$ & $37(5 \%)$ & $13(11 \%)$ \\
\hline Severe & $13(1 \%)$ & $7(1 \%)$ & $5(1 \%)$ & $1(1 \%)$ \\
\hline \multicolumn{5}{|l|}{ Educational level } \\
\hline Low & $786(47 \%)$ & $385(48 \%)$ & $344(46 \%)$ & $57(48 \%)$ \\
\hline Middle & $541(33 \%)$ & $234(29 \%)$ & $267(36 \%)$ & $40(34 \%)$ \\
\hline High & $204(12 \%)$ & $97(12 \%)$ & $99(13 \%)$ & $8(7 \%)$ \\
\hline \multicolumn{5}{|l|}{ Follow-up characteristics } \\
\hline $\begin{array}{l}\text { Number of mild hypoglycaemic events during } \\
\text { follow-up (in total group) }\end{array}$ & $0(0-12)$ & NA & $24(4-64)$ & $0(0-24)$ \\
\hline $\begin{array}{l}\text { Number of patients who reported mild } \\
\text { hypoglycaemia during follow-up }\end{array}$ & $803(48 \%)$ & NA & $744(100 \%)$ & $59(50 \%)$ \\
\hline $\begin{array}{l}\text { Number of mild hypoglycaemic events during } \\
\text { follow-up (in patients reporting hypoglycaemia) }\end{array}$ & $24(5-65)$ & NA & $24(4-64)$ & $24(12-101)$ \\
\hline $\begin{array}{l}\text { Number of severe hypoglycaemic events during } \\
\text { follow-up }\end{array}$ & $0(0-0)$ & NA & NA & $2(2-13)$ \\
\hline Follow-up duration, years & $1.9(1.1-2.4)$ & $1.8(1.1-2.3)$ & $1.9(1.2-2.5)^{\star}$ & $2.1(1.5-2.6)^{*}$ \\
\hline Mortality & $98(5.9 \%)$ & $67(8.3 \%)$ & $24(3.2 \%)^{\star}$ & $7(5.9 \%)$ \\
\hline
\end{tabular}

Data are presented as numbers $(\%)$, mean \pm SD or median (IQR).

*Significantly different $(p<0.05)$ compared with the patients who reported no hypoglycaemia during follow-up; differences in characteristics between the groups were tested using $\chi^{2}$ for dichotomous and nominal categorical variables, using $\chi^{2}$ including tests for trends for ordinal categorical variables, using independent-samples Student's t-tests for continuous variables, and Mann-Whitney's U tests for continuous variables that were not normally distributed.

tOther oral antidiabetic medication=other than metformin and SU, whether or not combined with metformin and/or SU. fHypertension is defined as either an SBP $\geq 140 \mathrm{~mm} \mathrm{Hg}$, a DBP $\geq 90 \mathrm{~mm} \mathrm{Hg}$ or use of antihypertensive medication.

$\S P a t i e n t s$ can be in more than one subcategory if they have experienced more than one type of cardiovascular event.

IFollow-up duration is defined as either the time between baseline and 1/1/2013, or, if someone died before 1/1/2013, as the time between baseline and mortality.

BMI, body mass index; CVA, cerebral vascular accident; DBP, diastolic blood pressure; eGFR, estimated glomerular filtration rate; HbA1c, glycated haemoglobin; MI, myocardial infarction; NA, not applicable; SBP, systolic blood pressure; SU, sulfonylurea; TIA, transient ischaemic attack; UAC, urinary albumin-creatinine. 
insulin, while there were no significant differences in glycaemic control. In addition, patients reporting only mild hypoglycaemic sensations were significantly younger, more often used only metformin next to their insulin, less often used only SU next to their insulin, and had a lower mortality rate.

\section{Prevalence of hypoglycaemic sensations}

Figure 1 shows that at baseline, 59\% of the patients $(\mathrm{N}=981)$ reported that they experienced no hypoglycaemic sensations during the past year, 37\% (N=612) reported only mild hypoglycaemic sensations, 3\% $(\mathrm{N}=55)$ reported only severe hypoglycaemic sensations, and $1 \%(\mathrm{~N}=19)$ reported both mild and severe hypoglycaemic sensations.

During a median follow-up of 1.9 years (IQR 1.12.4 years $), 48 \%$ of the patients $(\mathrm{N}=804)$ reported no hypoglycaemic sensations (table 1), 45\% (N=744) reported only mild hypoglycaemic sensations and $7 \%$ $(\mathrm{N}=119)$ reported severe hypoglycaemic sensations. Of the latter group, $50 \%(\mathrm{~N}=59)$ also reported mild hypoglycaemic sensations during follow-up, while the others $(\mathrm{N}=60)$ only reported severe hypoglycaemic sensations.

\section{Hypoglycaemic sensations and mortality}

During follow-up, $5.9 \%$ of the patients died $(\mathrm{N}=98)$. Patients who died during follow-up were significantly older at baseline (mean 75.9 vs 66.7 years old) compared with patients who were still alive at the end of follow-up, but did not significantly differ in diabetes duration or HbA1c levels at baseline (data not shown).

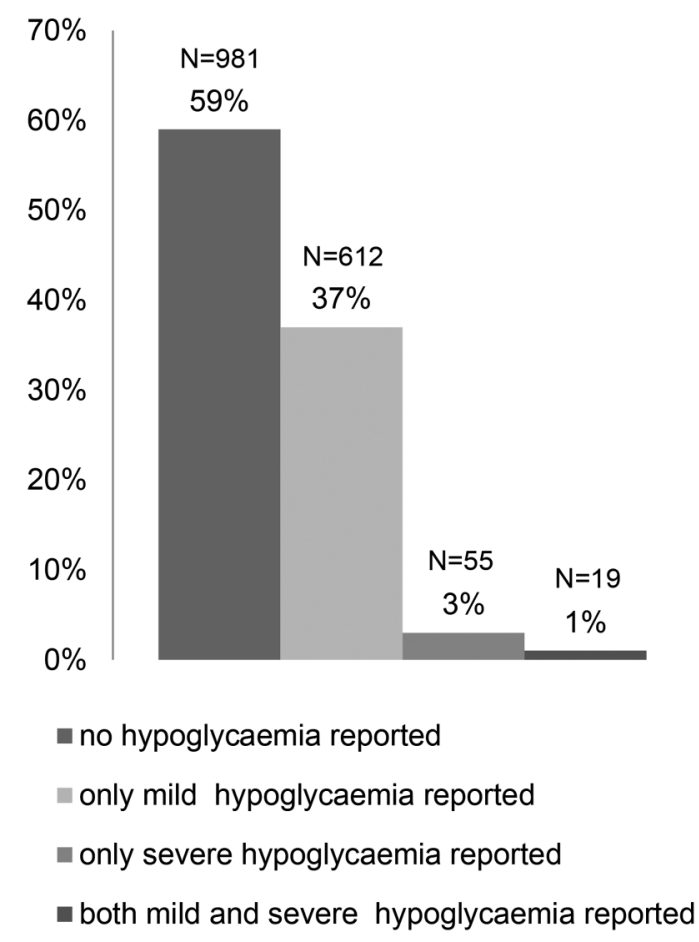

Figure 1 Baseline prevalence of self-reported hypoglycaemia.
The results of the logistic regression analyses are presented in table 2. Reporting only mild hypoglycaemic sensations was significantly associated with a lower mortality risk during follow-up (OR $0.37,95 \%$ CI 0.23 to 0.59 ), compared with reporting no hypoglycaemic sensations, while reporting severe hypoglycaemic sensations was non-significantly associated with a lower mortality risk (OR $0.69,95 \%$ CI 0.31 to 1.54 ). After univariate adjustment for possible confounders, the lower mortality risk in the group reporting mild hypoglycaemic sensations remained significant in all models, and the $\mathrm{OR}$ in the group reporting severe hypoglycaemic sensations remained non-significant (data not shown). After multivariate adjustment for age, sex, diabetes duration, HbAlc level, hypertension, smoking, use of SU, and microvascular and macrovascular complications, the ORs for mortality during follow-up were 0.48 (95\% CI 0.28 to 0.80 ) and 0.76 (95\% CI 0.33 to 1.80 ), respectively, for patients reporting only mild hypoglycaemic sensations and patients reporting severe hypoglycaemic sensations, compared with patients reporting no hypoglycaemic sensations during follow-up.

\section{Sensitivity analyses}

Reporting severe hypoglycaemic sensations, but not requiring medical help, was non-significantly associated with a lower mortality risk (OR $0.57,95 \%$ CI 0.23 to 1.46), while reporting severe hypoglycaemic sensations requiring medical assistance was non-significantly associated with a higher mortality risk (OR 1.38, 95\% CI 0.31 to 6.11 ; table $3 \mathrm{~A}$ ), compared with patients reporting no hypoglycaemic sensations. Compared with the total group of patients who reported severe hypoglycaemic sensations, patients reporting severe hypoglycaemic sensations that required medical help were on average older, more often male, had a longer diabetes duration, a longer duration of insulin use, higher HbAlc levels, a lower BMI and a higher mortality rate (see online supplementary table A).

Second, reporting both mild and severe hypoglycaemic sensations was non-significantly associated with a lower mortality risk (OR $0.39,95 \%$ CI 0.09 to 1.62), while reporting only severe hypoglycaemic sensations was not associated with mortality (OR $1.00,95 \%$ CI 0.39 to 2.58 ; table $3 \mathrm{~B}$ ), compared with patients reporting no hypoglycaemic sensations.

Third, sensitivity analyses showed lower ORs on mortality for patients reporting more mild events during follow-up (table 3C), as well as when only mild events reported at baseline were taken into account.

Generalised linear models with follow-up duration as an offset variable showed that differences in follow-up duration between patients did not influence the results (data not shown).

Excluding patients who had missing values on all questions regarding hypoglycaemic sensations at the first annual visit after they had been using insulin for at least 
Table 2 Association between hypoglycaemia and mortality

$$
\text { OR }(95 \% \mathrm{Cl})
$$

\section{Crude model}

No hypoglycaemia during follow-up

(Reference)

Only mild hypoglycaemia during follow-up

Severe hypoglycaemia during follow-up

Adjusted model ${ }^{*}$

No hypoglycaemia during follow-up

Only mild hypoglycaemia during follow-up

(Reference)

Severe hypoglycaemia during follow-up

*Adjusted for age, sex, diabetes duration ( $</ \geq 10$ years), HbA1c level $(<7 \%(<53 \mathrm{mmol} / \mathrm{mol}) / \geq 7 \%(53 \mathrm{mmol} / \mathrm{mol}))$, hypertension $(\mathrm{SBP} \geq 140 \mathrm{~mm} \mathrm{Hg}, \mathrm{DBP} \geq 90 \mathrm{~mm} \mathrm{Hg}$ or use of antihypertensive medication), smoking, use of sulfonylurea, and microvascular or macrovascular complications (defined as retinopathy, history of CVD, eGFR value $<60$ or UACR $\geq 3.5 \mathrm{mg} / \mathrm{mmol}$ for women or $\geq 2.5 \mathrm{mg} / \mathrm{mmol}$ for men).

CVD, cardiovascular disease; DBP, diastolic blood pressure; eGFR, estimated glomerular filtration rate; HbA1c, glycated haemoglobin; SBP, systolic blood pressure; UACR, urinary albumin-creatinine ratio.

Table 3 Sensitivity analyses

\section{OR $(95 \% \mathrm{Cl})$}

p Value

(A) Association between mortality and hypoglycaemia, whether or not requiring medical help

No hypoglycaemia during follow-up

Only mild hypoglycaemia during follow-up

Severe hypoglycaemia during follow-up, but no medical help reported

Severe hypoglycaemia during follow-up, requiring medical help

(Reference)

$0.37(0.23$ to 0.59$)$

$<0.01$

$0.57(0.23$ to 1.46$)$

0.24

1.38 (0.31 to 6.11$)$

0.68

(B) Association between mild and severe hypoglycaemia, whether or not combined with mild hypoglycaemia, and mortality No hypoglycaemia during follow-up

Only mild hypoglycaemia during follow-up (Reference)

Mild and severe hypoglycaemia during follow-up

0.37 (0.23 to 0.59$)$

$<0.01$

Only severe hypoglycaemia during follow-up

(C) Dose-response association between mild hypoglycaemia and mortality

Number of events reported during follow-up*

No hypoglycaemia during follow-up

$\leq 2$ mild hypoglycaemic events per year

(Reference)

3-10 mild hypoglycaemic events per year

12-32 mild hypoglycaemic events per year

$0.38(0.16$ to 0.88$)$

0.03

$\geq 33$ mild hypoglycaemic events per year

0.14 (0.04 to 0.59$)$

$<0.01$

Number of events reported at baseline†

No hypoglycaemia

$\leq 2$ mild hypoglycaemic events

3-11 mild hypoglycaemic events

(Reference)

0.72 (0.30 to 1.68$)$

0.44

0.66 (0.26 to 1.67$)$

0.38

12-48 mild hypoglycaemic events

$0.29(0.11$ to 0.81$)$

0.02

$\geq 52$ mild hypoglycaemic events

$0.30(0.09$ to 0.97$)$

0.04

Table 3C: For both models, only patients who did not report severe hypoglycaemia were taken into account.

${ }^{*}$ For this analysis, the average number of mild hypoglycaemic events per year was calculated by dividing the total number of reported mild events during follow-up by the number of measurements. This number was categorised based on quartiles.

†For this analysis, the number of hypoglycaemic events reported at baseline was categorised based on quartiles.

1 year $(\mathrm{N}=405)$ did not change our results (data not shown).

Finally, no significant interaction was observed between mild and severe hypoglycaemic sensations, or between hypoglycaemic sensations and cardiovascular history, age $</ \geq 70$ years, sex or use of SU.

\section{DISCUSSION}

In this prospective cohort study among 1667 insulintreated patients with T2D from usual care, we found that $37 \%$ of the patients reported mild hypoglycaemic sensations during the past year, while $4 \%$ reported severe hypoglycaemic sensations. These numbers are somewhat lower compared with previous studies in which 51-64\% reported mild hypoglycaemia and $7-25 \%$ severe hypoglycaemia, ${ }^{16}$ or $50 \%$ reported any hypoglycaemia. ${ }^{22}$ In line with earlier studies, we observed that patients reporting hypoglycaemic sensations had a longer duration of diabetes as well as insulin use, ${ }^{16} 222^{23}$ and were more often treated with fast-acting insulin. ${ }^{24}$ 
In addition, we observed that patients with mild hypoglycaemic sensations had a $50 \%$ lower mortality risk during follow-up, compared with those without hypoglycaemic sensations. This finding is in line with previous studies on objectively measured ${ }^{3}$ and self-reported mild hypoglycaemia, ${ }^{4}$ but contradictory to other studies, which showed (non-significant) higher mortality rates for objectively measured ${ }^{5}$ and self-reported mild hypoglycaemia. ${ }^{13}$ These discrepancies might be explained by differences in diabetes duration, or the type of diabetes treatment, type of diabetes and care setting.

Surprisingly, we observed that severe hypoglycaemic sensations were also (non-significantly) associated with a lower risk on mortality during follow-up, compared with those without hypoglycaemic sensations. However, sensitivity analyses showed that this association could mainly be attributed to the patients who experienced both mild and severe hypoglycaemic sensations. Moreover, reporting severe hypoglycaemic sensations requiring medical assistance was associated (although not significant) with a $40 \%$ higher mortality risk. This positive association between hypoglycaemic sensations requiring medical help and mortality is in line with previous studies. $.^{3-5} 7-1113$ The fact that this association was non-significant in our study could be due to the low number of patients reporting this type of event.

One mechanism that could explain our observed association between hypoglycaemic sensations not requiring medical help and mortality is a protective effect of frequent mild hypoglycaemia against the effects of a severe hypoglycaemic event. ${ }^{3}$ However, although we observed a supporting dose-response association, we did not find an interaction between mild and severe hypoglycaemic sensations. Another mechanism could be impaired awareness of hypoglycaemia: $:^{25}$ experiencing mild hypoglycaemic sensations could increase the patients' awareness regarding their risk of hypoglycaemia and other diabetes complications, which in turn might positively affect their health behaviour and reduce their mortality risk; while impaired awareness could prevent patients from taking actions to resolve their hypoglycaemia. This mechanism is supported by previous studies showing that impaired awareness is associated with increased incidence of severe hypoglycaemia. ${ }^{25}{ }^{26}$ More research is, however, needed to find support for this possible mechanism.

Our study has some limitations that warrant discussion. Our study was observational; therefore, direct causal relationships cannot be established, and unmeasured confounding might have influenced the results. Second, we asked the patients about hypoglycaemic sensations during the past year, which might have led to an underestimation of the prevalence of hypoglycaemic sensations. ${ }^{27}$ Third, we did not objectively measure hypoglycaemia. It might be that some patients confused, for instance, 'normal feelings' of hunger with mild hypoglycaemia, or that some patients experienced pseudohypoglycaemia. However, we think that for clinical practice it is very relevant to also look at patient-reported hypoglycaemic sensations rather than objectively measured events only. Finally, we were unable to take the cause of death into account and the size of our population did not permit correction for all possible confounders combined. However, in a full corrected model, the association was slightly attenuated but still statistically significant.

The strengths of our study include the representative population to evaluate the incidence of hypoglycaemic sensations in patients with T2D treated with insulin, as well as the use of self-reported hypoglycaemic sensations, which might better reflect hypoglycaemic sensations as experienced in everyday life than the use of objectively measured events only, the fact that several sensitivity analyses were performed to study the association between mild and severe hypoglycaemic sensations and mortality, and the prospective design with repeated measurements of the exposure.

We believe that our results are relevant for clinical practice. While we studied patient-reported hypoglycaemic sensations rather than objectively measured events only, we showed that self-reported hypoglycaemic sensations are highly prevalent in the insulintreated T2D population, and that self-reported hypoglycaemic sensations not requiring medical assistance are not associated with an increased risk of mortality, suggesting that these sensations are not an indicator of increased short-term mortality risk in patients with T2D.

We would, however, like to emphasise that hypoglycaemia can be troublesome for patients and that hypoglycaemia and fear of hypoglycaemia have been shown to reduce quality of life. ${ }^{28}$ For future research, it is important to further study the different associations with mortality of self-reported hypoglycaemic sensations compared with objectively measured events.

\section{Author affiliations}

${ }^{1}$ Department of Epidemiology and Biostatistics, VU University Medical Centre, Amsterdam, The Netherlands

${ }^{2}$ EMGO+ Institute for Health and Care Research, VU University Medical Centre, Amsterdam, The Netherlands

${ }^{3}$ Novo Nordisk A/S, Søborg, Denmark

${ }^{4}$ Department of General Practice and Elderly Care Medicine, VU University Medical Center, Amsterdam, The Netherlands

Acknowledgements This project was supported by the Diabetes Care System West-Friesland, the Netherlands.

Contributors SPR conceived and designed the study, researched the data and wrote the manuscript. FR, BLT, MLW, MWH and JMD conceived and designed the study and reviewed and edited the manuscript. GN, AAWAvdH, IW and PJE contributed to discussion and reviewed and edited the manuscript. BLT and MLW took part in the interpretation of data, writing of the manuscript and decision to submit the article for publication. SPR had full access to the data. JMD is the guarantor of this work. All the authors reviewed and approved the final version submitted for publication.

Funding This work was supported by funding from Novo Nordisk A/S.

Disclaimer The study funder had no part in the collection and analysis of the data. 
Competing interests BLT and MLW are employees and shareholders of Novo Nordisk A/S. JMD reports grants from Novo Nordisk A/S for the conduct of this study.

Provenance and peer review Not commissioned; externally peer reviewed.

Data sharing statement No additional data are available.

Open Access This is an Open Access article distributed in accordance with the Creative Commons Attribution Non Commercial (CC BY-NC 4.0) license, which permits others to distribute, remix, adapt, build upon this work noncommercially, and license their derivative works on different terms, provided the original work is properly cited and the use is non-commercial. See: http:// creativecommons.org/licenses/by-nc/4.0/

\section{REFERENCES}

1. Rombopoulos G, Hatzikou M, Latsou D, et al. The prevalence of hypoglycemia and its impact on the quality of life (QoL) of type 2 diabetes mellitus patients (the HYPO study). Hormones 2013;12:550-8.

2. Barnett $\mathrm{AH}$, Cradock S, Fisher $\mathrm{M}$, et al. Key considerations around the risks and consequences of hypoglycaemia in people with type 2 diabetes. Int J Clin Pract 2010;64:1121-9.

3. Bonds DE, Miller ME, Bergenstal RM, et al. The association between symptomatic, severe hypoglycaemia and mortality in type 2 diabetes: retrospective epidemiological analysis of the ACCORD study. BMJ 2010;340:b4909.

4. Zoungas S, Patel A, Chalmers J, et al. Severe hypoglycemia and risks of vascular events and death. N Engl J Med 2010;363:1410-8.

5. Mellbin LG, Rydén L, Riddle MC, et al, The ORIGIN Trial Investigators. Does hypoglycaemia increase the risk of cardiovascular events? A report from the ORIGIN trial. Eur Heart $J$ 2013;34:3137-44

6. Duckworth WC, Abraira C, Moritz TE, et al. The duration of diabetes affects the response to intensive glucose control in type 2 subjects: the VA Diabetes Trial. J Diabetes Complicat 2011;25:355-61.

7. Johnston SS, Conner C, Aagren M, et al. Evidence linking hypoglycemic events to an increased risk of acute cardiovascular events in patients with type 2 diabetes. Diabetes Care 2011;34:1164-70

8. Zhao Y, Campbell CR, Fonseca V, et al. Impact of hypoglycemia associated with antihyperglycemic medications on vascular risks in veterans with type 2 diabetes. Diabetes Care 2012;35:1126-32.

9. Rathmann W, Kostev K, Gruenberger JB, et al. Treatment persistence, hypoglycaemia and clinical outcomes in type 2 diabetes patients with dipeptidyl peptidase-4 inhibitors and sulphonylureas: a primary care database analysis. Diabetes Obes Metab 2013;15:55-61.

10. Hsu PF, Sung SH, Cheng HM, et al. Association of clinical symptomatic hypoglycemia with cardiovascular events and total mortality in type 2 diabetes: a nationwide population-based study. Diabetes Care 2013;36:894-900.

11. Khunti K, Davies M, Majeed A, et al. Hypoglycemia and risk of cardiovascular disease and all-cause mortality in insulin-treated people with type 1 and type 2 diabetes: a cohort study. Diabetes Care 2015;38:316-22.

12. Goto A, Onyebuchi AA, Maki G, et al. Severe hypoglycaemia and cardiovascular disease: systematic review and meta-analysis with bias analysis. BMJ 2013;347:f4533.

13. McCoy RG, Van Houten HK, Ziegenfuss JY, et al. Increased mortality of patients with diabetes reporting severe hypoglycemia. Diabetes Care 2012;35:1897-901.

14. UK Prospective Diabetes Study (UKPDS) Group. Intensive blood-glucose control with sulphonylureas or insulin compared with conventional treatment and risk of complications in patients with type 2 diabetes (UKPDS 33). Lancet 1998;352:837-53.

15. Frye RL, August P, Brooks MM, et al, The BARI 2D Study Group. A randomized trial of therapies for type 2 diabetes and coronary artery disease. N Engl J Med 2009;360:2503-15

16. UK Hypoglycaemia Study Group. Risk of hypoglycaemia in types 1 and 2 diabetes: effects of treatment modalities and their duration. Diabetologia 2007;50:1140-7.

17. Bloomgarden Z, Einhorn D. Hypoglycemia in type 2 diabetes: current controversies and changing practices. Front Endocrino (Lausanne) 2012;3:66.

18. Walraven I, Mast MR, Hoekstra T, et al. Distinct HbA1c trajectories in a type 2 diabetes cohort. Acta Diabetol 2015;52:267-75.

19. American Diabetes Association. Defining and reporting hypoglycemia in diabetes: a report from the American diabetes association workgroup on hypoglycemia. Diabetes Care 2005;28:1245-9.

20. WHO Collaborating Centre for Drug Statistics Methodology. Anatomical Therapeutic Chemical (ATC) Classification System. 19-12-2013. 1-8-2015.

21. Aldington SJ, Kohner EM, Meuer S, et al. Methodology for retinal photography and assessment of diabetic retinopathy: the EURODIAB IDDM complications study. Diabetologia 1995;38:437-44.

22. Lundkvist J, Berne C, Bolinder B, et al. The economic and quality of life impact of hypoglycemia. Eur J Health Econ 2005;6: 197-202.

23. Amiel SA, Dixon T, Mann R, et al. Hypoglycaemia in type 2 diabetes. Diabet Med 2008;25:245-54.

24. Mclntosh B, Cameron C, Singh SR, et al. Choice of therapy in patients with type 2 diabetes inadequately controlled with metformin and a sulphonylurea: a systematic review and mixed-treatment comparison meta-analysis. Open Med 2012;6:e62-74.

25. Graveling AJ, Frier BM. Impaired awareness of hypoglycaemia: a review. Diabetes Metab 2010;36(Suppl 3):S64-74.

26. Henderson JN, Allen KV, Deary IJ, et al. Hypoglycaemia in insulin-treated type 2 diabetes: frequency, symptoms and impaired awareness. Diabet Med 2003;20:1016-21.

27. Cariou $\mathrm{B}$, Fontaine $\mathrm{P}$, Eschwege $\mathrm{E}$, et al. Frequency and predictors of confirmed hypoglycaemia in type 1 and insulin-treated type 2 diabetes mellitus patients in a real-life setting: results from the DIALOG study. Diabetes Metab 2015;41:116-25.

28. Solli O, Stavem K, Kristiansen IS. Health-related quality of life in diabetes: the associations of complications with EQ-5D scores. Health Qual Life Outcomes 2010;8:18. 